
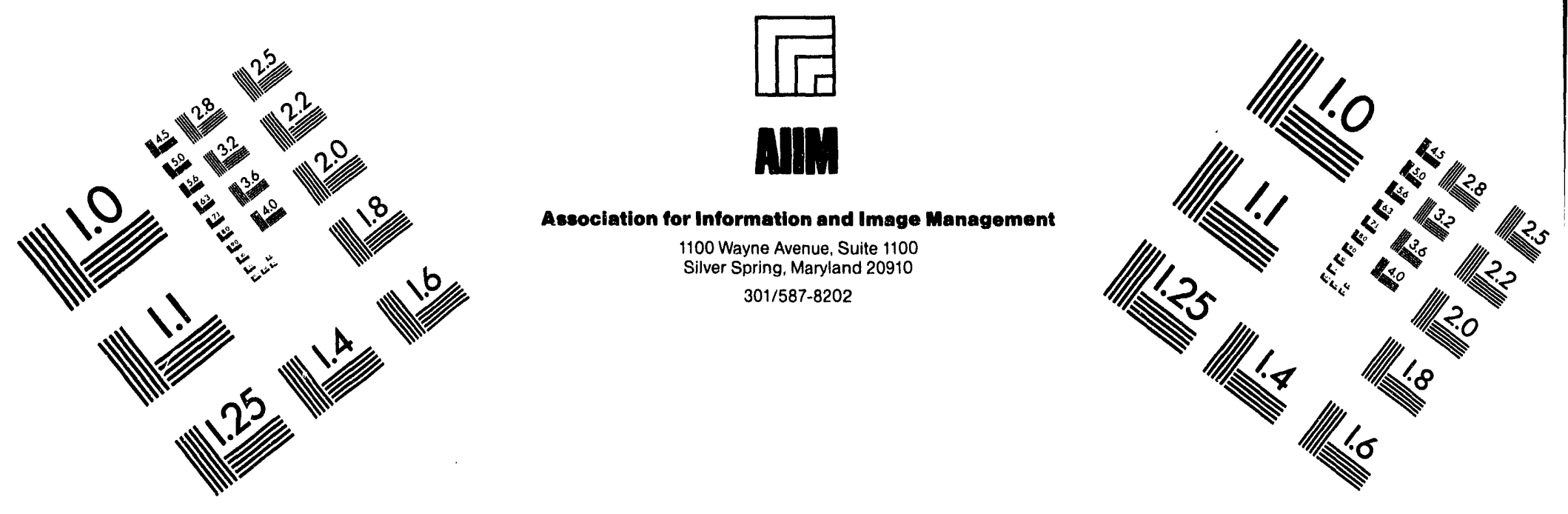

\title{
Centimeter
}

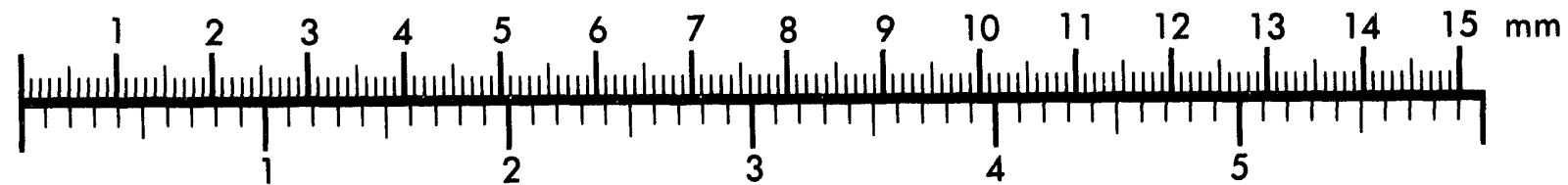
Inches
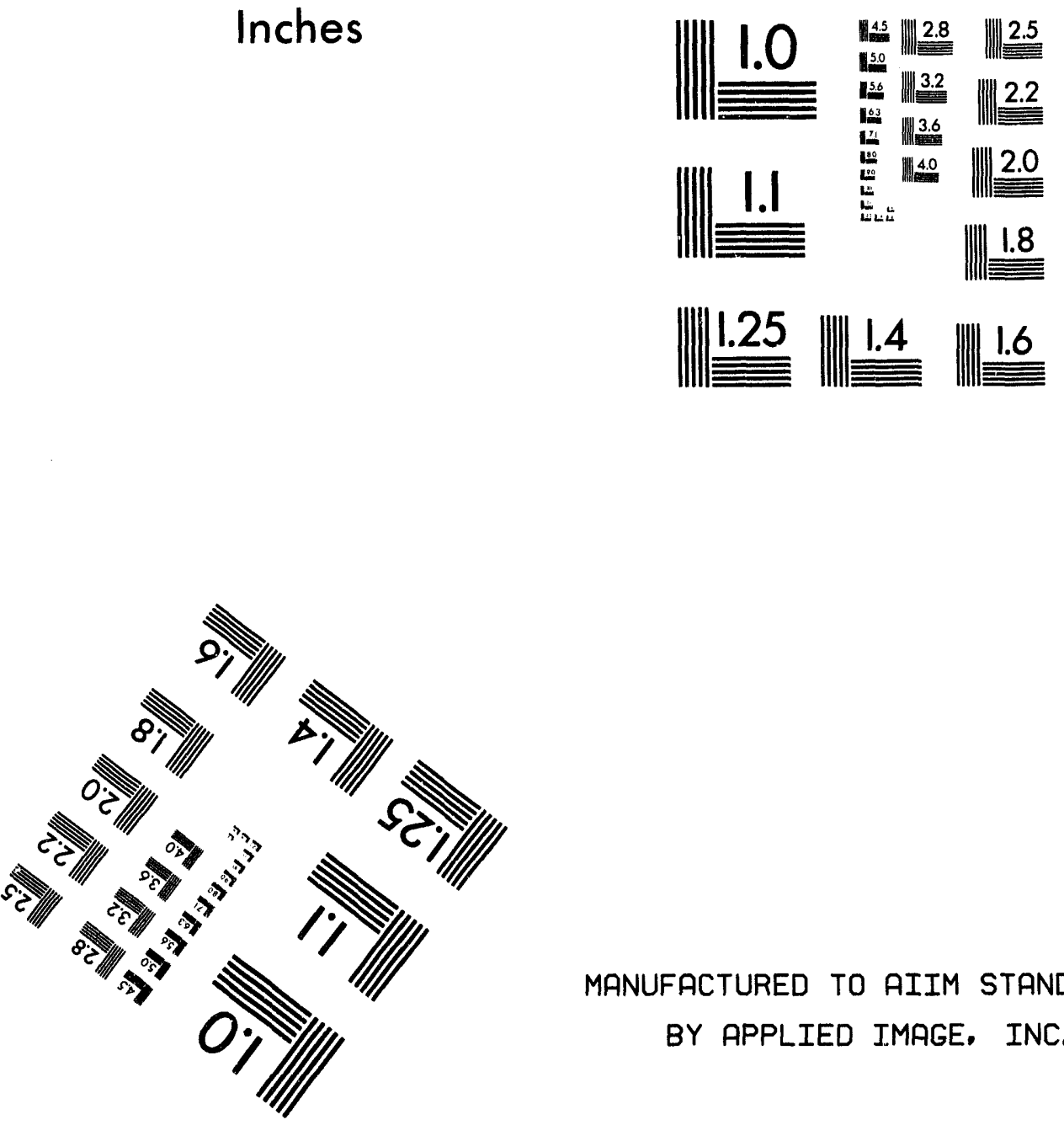

MANUFACTURED TO AIIM STANDARDS

BY APPLIED IMAGE, INC.

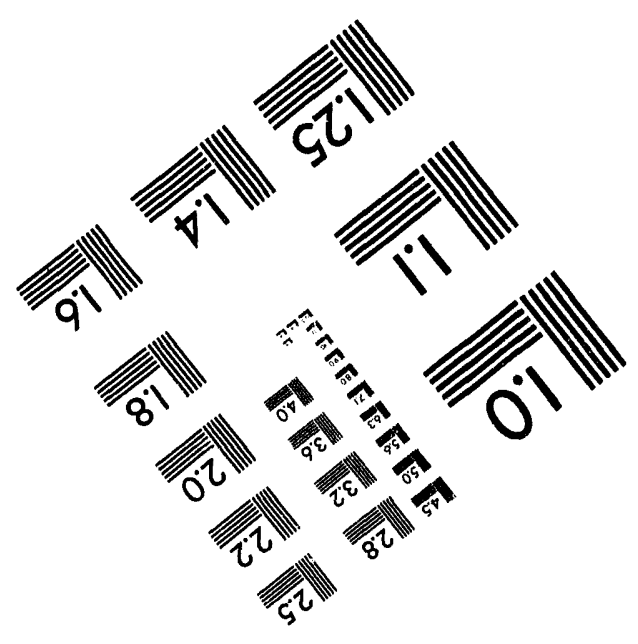



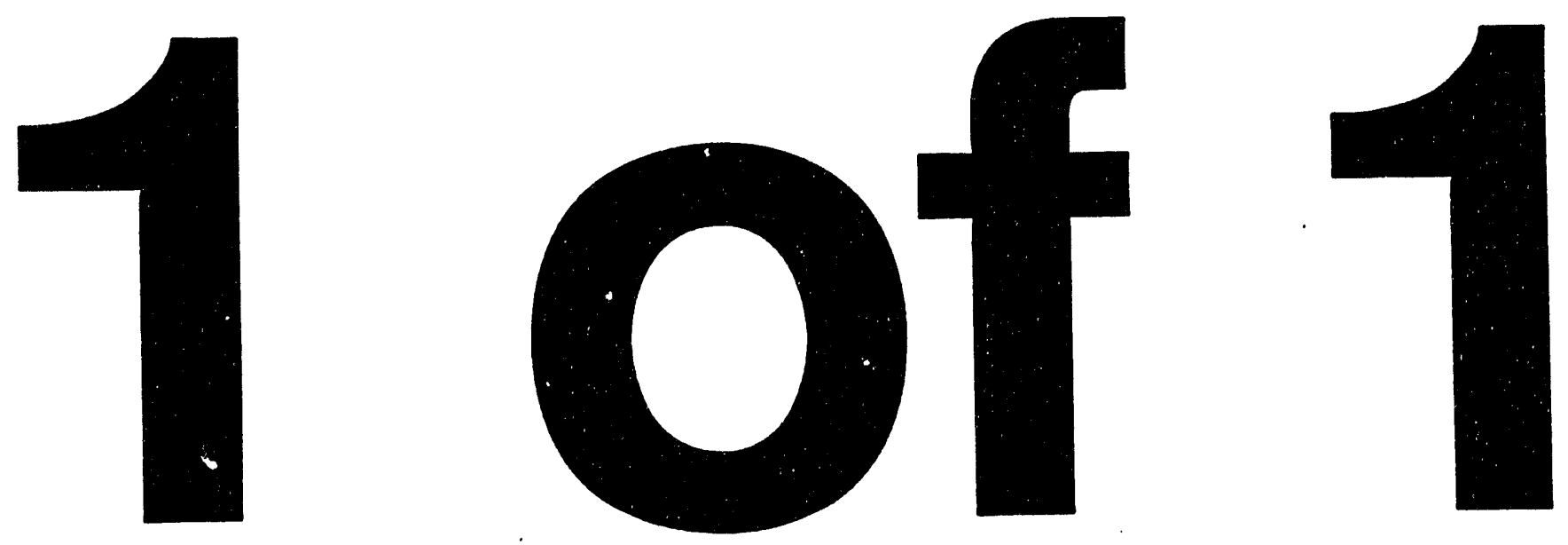


$$
\text { Conf } 940411-50
$$

\title{
UCRL-JC-115364
}

PREPRINT

\section{Magnetic X-Ray Circular Dichroism in Fe Co Pt Multilayers}

\author{
J.G. Tobin \\ A.F. Jankowski \\ G.D. Waddill \\ P.A. Sterne
}

This paper was prepared for submittal to the 1994 Spring Meeting of the Materials Research Society San Francisco, CA

April 4-8, 1994

April 1994

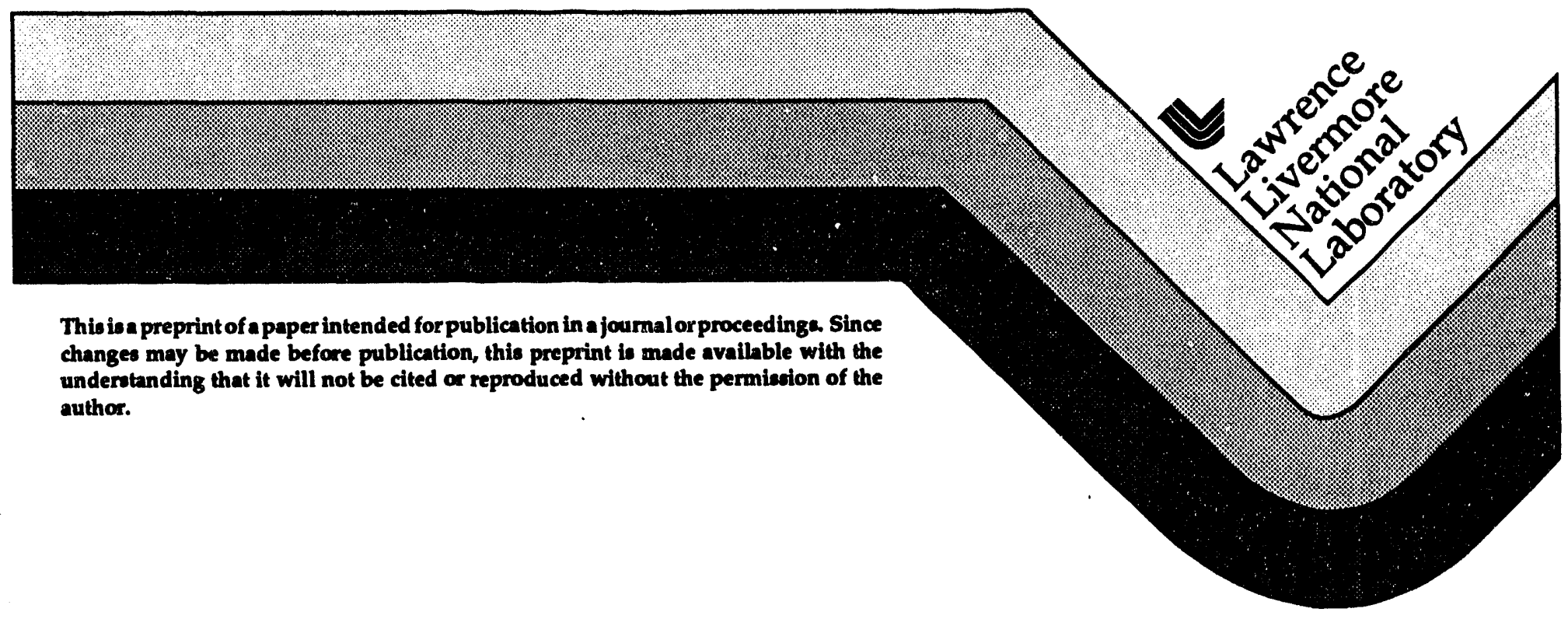




\section{DISCLAIMER}

This document was prepared as $m$ account of work sponsored by an agency of the United States Government. Neither the United States Government nor the University of Colifornia nor any of their employees, makes any warranty, express or implied, or assumes any legal liability or responsibility for the accuracy, completeness, or usefulness of any information, apparatus, product, or process disclosed, or represents that its use would not infringe privately owned rights. Reference herein to any specific commercial products, process, or service by trade name, trademark, manufacturer, or otherwise, does not necessarily constitute or imply its endorsement, recommendation, or favoring by the United States Governursent or the University of California. The views and opinions of authors expressed herein do not necessarily state or reflect those of the United States Government or the University of California, and shall not be used for advertising or product endorsement purposes. 


\title{
MAGNETIC X-RAY CIRCULAR DICHROISM
}

IN FE CO PT MULTILAYERS

\author{
J.G. TOBIN* A.F. JANKOWSKI*, G.D. WADDIL*, P.A. STERNE** \\ *Lawrence Livermore National Laboratory, Livermore, CA 94550 \\ **University of California, Davis, CA 95616
}

\begin{abstract}
Magnetic x-ray circular dichroism in x-ray absorption has been used to investigate the ternary multilayer system, Fe Co Pt. Samples were prepared by planar magnetron sputter deposition and carefully characterized, using a variety of techniques such as grazing-incidence and high-angle $x$ ray scattering, Auger depth profiling and cross-section transmission electron microscopy. As

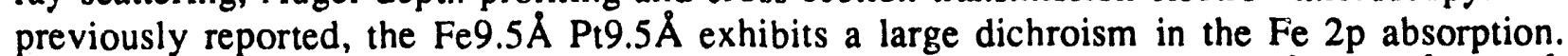

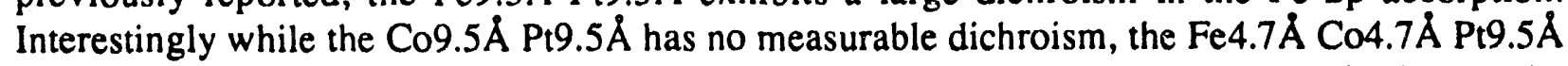
sample has a dichroism at both the Fe $2 p$ and Co $2 p$ absorption edges. These and other results will be compared to slab calculation predictions. Possible explanations will be discussed.
\end{abstract}

\section{INTRODUCTION}

The last several years have witnessed a massive growth in the research and development of nanoscale magnetic materials. Perhaps the best review is provided by the Falicov Report ${ }^{l}$ on "Surface, Interface, and Thin-Film Magnetism." Three general lessons can be derived from this report: (1) Magnetism is one of those special cases where fundamental research can directly lead to technological applications; (2) The key to understanding and manipulation of magnetic properties is the subtle yet overwhelming interplay of atomic geometric structure and local magnetic properties. For example, the giant magneto-resistance effect (GMR), which is already being explored for technological exploitation $2,3,4$, appears to be intimately coupled to interfacial and thin film effects and probably will require elementally-specific probes for an explicit determination of the underlying causes $5,6,7$. This also appears to be the case for spin valves $8,9,10$, another source of device miniaturization in read heads and magnetic sensors. [While it may eventually be found that these two effects are fundamentally connected, for now it appears that the GMR effect (up to 60\%) is dependent upon an anti-ferromagnetic coupling through a nonferromagnetic layer while the spin valve effect $(\leq 10 \%)$ is associated with an uncoupled ferromagnetic layer ${ }^{9}$, which can be controlled externally.]; (3) The importance of probes with a direct spin-dependence. A very recent illustration of this is the development of the magnetic $x$ ray circular dichroism (MXCD) using $x$-ray absorption $11-15$ and photoemission $16,1 i$ as a probe of surface, monolayer, and multilayer magnetism. It is this advantage of elemental selectivity and spin specificity from MXCD x-ray absorption that we have to utilized, coupled to extensive structural characterization using techniques such as $\mathrm{x}$-ray diffraction and transmission electron microscopy ${ }^{18}$, plus spin-dependent slab calculations ${ }^{19}$, to investigate $\mathrm{Fe}$ Co $\mathrm{Pt}$ magnetic multilayers. 


\section{SAMPLE PREPARATION AND CHARACTERIZATION}

The Fe Co $\mathrm{Pt}$ multilayer samples are prepared using magnetron sputter deposition. The deposition chamber is cryogenically pumped to a base pressure of $1.3 \times 10^{-5} \mathrm{~Pa}$. A circular array of magnetron sources is situated $20 \mathrm{~cm}$ beneath an oxygen-free copper platen. The magnetron sources are operated in the dc mode at a 330-390 Volt discharge. An argon working gas pressure of $0.40 \mathrm{~Pa}$ is used at a flow rate of $15.5 \mathrm{cc} \mathrm{min.-1}$. The substrates are sequentially rotated over each source at $1.0 \mathrm{rev} . \mathrm{min}^{-1}$. The target materials are $>0.9994$ pure. The polished Si substrates are cleaned with a procedure consisting of a detergent wash, deionized water rinse, alcohol rinse, and a $\mathrm{N}_{2}$ gas drying prior to deposition. The substrates remain at a temperature between 293 and $306 \mathrm{~K}$ during the deposition. The sputter deposition rates, between 0.02 and $0.50 \mathrm{~nm} \mathrm{sec}{ }^{-1}$, are monitored using calibraied quartz crystals. The quartz crystals indicate the component layer thicknesses and the layer pair thicknesses, $\mathrm{d}_{\mathrm{FeCoPt}} \mathrm{XTC}$. The multilayer films are grown to a $0.2 \mu \mathrm{m}$ thickness. Samples were futher characterized with $\mathrm{x}$-ray diffraction, transmission electron microscopy and Auger depth profiling, as described elsewhere $18,20,21$.

\section{MXCD AND SLAB CALCULATION RESULTS}

The MXCD measurements were performed at Stanford Synchrotron Radiation Laboratory (SSRL) on a spherical grating monochromator having the ability to generate soft $\mathrm{X}$-rays with a high degree of circular polarization. This beamline (BL 8-2) is part of the UC/National Laboratories facilities at SSRL 22,23. The absorption measurements were made in a total electron yield mode. Samples were magnetized in situ with a pulse coil, and the absorption was measured in remanence. For $3 d$ transition metals, $\mathrm{MXCD}$ in x-ray absorption is observed as a polarizationdependent intensity variation in the $L_{2}$ and $L_{3}$ edges. A typical example of the $\mathrm{Fe} \mathrm{Co} \mathrm{Pt}$ multilayers is shown in Figure 1. The polarization dependence requires that the incident $x$-ray helicity (either parallel or anti-parallel to the direction of propagation) be aligned or anti-aligned with the sample magnetization $18,20,21$. When these vectors are perpendicular, the polarization dependence vanishes. The spectra in Figure 1 are for a grazing $x$-ray incidence angle of $80^{\circ}$ from the sample normal. The solid curve is for a nearly anti-parallel arrangement of x-ray helicity and majority electron spin, and the dashed curve for a nearly parallel geometry. The intensity differences for for the $L_{2}$ and $L_{3}$ white lines are apparent. Our measurements demonstrate that the magnetization for the $\mathrm{Fe} \mathrm{Co} \mathrm{Pt}$ samples is in the plane of the multilayer films. It has also been shown that the relative strengths of the $L_{2}$ and $L_{3}$ absorption edges contain information about the spin-dependent density of states above the Fermi level and, therefore, about the spin and orbital magnetic moments of the material $18,20,21$. Interestingly in the case of Figure 1, there is an observable MXCD effect at both the Fe $2 p$ and Co $2 p$ edges. Preliminary analysis indicates for $\mathrm{Fe}_{\mathrm{x}} \mathrm{Co}_{\mathrm{y}} \mathrm{Pt}$ t9.5A, little or nor $\mathrm{MXCD}$ effect if $\mathrm{x}=0$ and $0 \leq y \leq$ $10 \AA$ or if $0<x<4 \AA$ and $2 \AA \leq y \leq 4 \AA$. A significant $M X C D$ effect is observable for $y=0$ and $5 \AA \leq x \leq 12 \AA$ or $4 \AA<x$ and $4 \AA<y$. Further analysis, using branching ratio and sum rule approaches, is in progress $18,20,21$. 


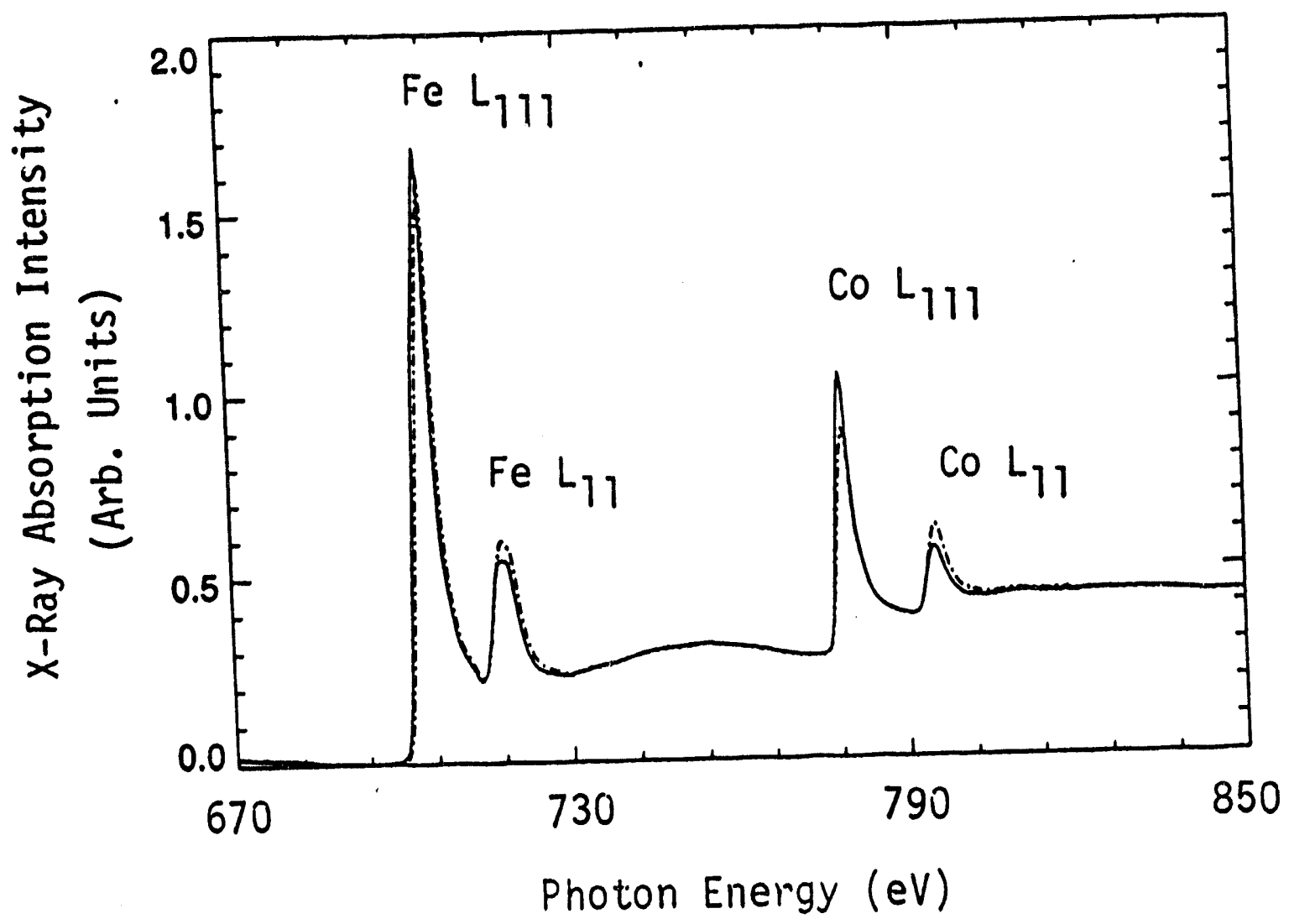

Figure 1. The x-ray absorption spectra of $F e 4.7 \AA$ C $04.7 \AA$ Pt9.5A using circularly-polarized $x$ rays. See text for details.

This raises an important question: Is the observation of an $\mathrm{MXCD}$ effect a true moment transfer or only a proximity effect from the nearby polarized Fe conduction states? To address this issue, we have begun a modeling of the system using a slab calculational method. Preliminary results are show/n in Figure 2. Here the structures are all fcc with $a=3.81 \AA$, extracted from $x$-ray diffraction results. In this case large moments are seen for both $F e$ and Co in both the binary ( $x=$ 0 or $y=0$ ) and ternary cases. Further calculations with adjustments of spacings will be necessary before any additional insight can be gained. 
MXCD in Fe Co Pt Multilayers

Preliminary Slab Calculation Results

Magnetic Moments (in Bohr magnetons)

\begin{tabular}{|c|c|c|c|c|}
\hline- & 0.15 & --- & $\mathrm{Pt}$ & 0.16 \\
\hline- & 0.007 & $\cdots$ & $\mathrm{Pt}$ & 0.01 \\
\hline & 0.15 & - & $\mathrm{Pt}$ & 0.01 \\
\hline 0000 & 2.82 & $\cdots$ & $\mathrm{Pt}$ & 0.16 \\
\hline 0000 & 2.78 & $* * * *$ & Co & 1.92 \\
\hline \multirow[t]{3}{*}{0000} & 2.82 & $* * * *$ & Co & 1.88 \\
\hline & & $* * * *$ & Co & 1.88 \\
\hline & & $* * * *$ & Co & 1.92 \\
\hline- & 0.15 & - & $\mathrm{Pt}$ & 0.16 \\
\hline & -0.04 & $\cdots$ & $\mathrm{Pt}$ & 0.00 \\
\hline- & -0.04 & - & $\mathrm{Pt}$ & 0.02 \\
\hline$\cdots$ & 0.15 & $\cdots$ & $\mathrm{Pt}$ & 0.15 \\
\hline 0000 & 2.84 & 0000 & $\mathrm{Fe}$ & 2.83 \\
\hline 0000 & 2.78 & 0000 & $\mathrm{Fe}$ & 2.77 \\
\hline 0000 & 2.78 & $* * * *$ & Co & 1.85 \\
\hline 0000 & 2.84 & $* * * *$ & Co & 1.94 \\
\hline
\end{tabular}

Figure 2. Slab calculation results for ( $\left.\mathrm{Fe}_{3 \mathrm{ML}} \mathrm{Pt}_{3 \mathrm{ML}}\right) \mathrm{n}$, (Fe $4 \mathrm{ML}$ Pt4ML)n, (Co4ML Pt4ML)n and $\left(\mathrm{Fe}_{2 \mathrm{ML}} \mathrm{CO}_{2 \mathrm{ML}} \mathrm{Pt} 4 \mathrm{ML}\right) \mathrm{n}$. ML stands for monolayer. $1 \mathrm{ML} \approx 2.2 \AA$ in these systems.

\section{SUMMARY}

We are using a combined approach based upon magnetic $x$-ray circular dichroism with $\mathbf{x}$-ray absorption, structural characterization and theoretical simulations with slab calculations to probe the structure-property relationships in magnetic $\mathrm{Fe}$ Co Pt multilayers. Thickness dependences, template effects, and interfacial mixing are all crucial contributions that need to be isolated, controlled and understood. The issue of moment transfer versus proximity conduction band polarization is being investigated further.

\section{ACKNOWLEDGEMENTS}

Work was performed under the auspices of the US Department of Energy by the Lawrence Livermore National Laboratory under contract number W-7405-ENG-48. We wish to thank Karen Clark for her clerical support of this work. Conversations with Jim Brug were greatly appreciated. 


\section{REFERENCES}

1. L.M. Falicov, D.T. Pierce, S.D. Bader, R. Gronsky, K.B. Hathaway, H.J. Hopster, D.N. Lambeth, S.S.P. Parkin, G. Prinz, M. Salamon, I.K. Schuller, and R.H. Victora, J. Mat. Res. 5, 1299 (1990).

2. G. Avalos, San Ramon Valley Times, Friday, August 20, 1993.

3. R. Pool, Science 261, 984 (20-AUG-1993).

4. T.L. Hylton, K.R. Coffey, M.A. Parker, and J.K. Howard, Science 2ó1, 1021 (20AUG-1993).

5. S.S.P. Parkin, Phys. Rev. Lett. 71, 1641 (1993).

6. A.C. Ehrlich, Phys. Rev. Lett. 71, 2300 (1993).

7. V. Grolier, D. Renard, B. Bartenlian, P. Beauvillian, C. Chappert, C. Dupas, J. Ferre, M. Galtier, E. Kolb, M. Mulloy, J.P. Renard, and P. Veillet, Phys. Rev. Lett. 71, 3023 (1993).

8. B.A. Gurney, V.S. Speriosu, J.P. Nozieres, H.F. Lefakis, D.R. Wilhoit, and D.U. Need, Phys. Rev. Lett. Z1, 4023 (1993).

9. B. Dieny, V.S. Speriosu, S. Metin, S.S.P. Parkin, B.A. Gurney, P. Baumgart, and D.R. Wilhoit, J. Appl. Phys. 69, 4774 (1991).

10. B. Dieny, V.S. Speriosu, S.S.P. Parkin, B.A. Gurney, D.R. Wilhoit, and D. Mauri, Phys. Rev. B 43, 1297 (1991).

11. G. Schutz, W. Wagner, W. Wilhelm, P. Keinle, R. Zeller, R. Frahm, and G. Materlik, Phys. Rev. Lett. 58, 737 (1987); G. Schutz, M. Knulle, R. Wienke, W. Wilhelm, W. Wagner, P. Kienle, and R. Frahn, Z. Phys. B 73, 67 (1988); G. Schutz, R. Frahm, P. Mautner, R. Wienke, W. Wagner, W. Wilhelm, and P. Kienle, Phys. Rev. Lett. 62, 2620 (1989).

12. C.T. Chen, F. Sette, Y. Ma, and S. Modesti, Phys. Rev. B 42, 7262 (1990); C.T. Chen, Y.U. Idzerda, H.J. Lin, G. Meigs, A. Chaiken, G.A. Prinz, and G.H. Ho, Phys. Rev. B 48, 642 (1993).

13. J.G. Tobin, G.D. Waddill, and D.P. Pappas, Phys. Rev. Lett. 68,3642 (1992).

14. Y. Wu, J. Stohr, B.D. Hermsmeier, M.G. Samant, and D. Weller, Phys. Rev. Lett. 69 , 2307 (1992).

15. J. Stohr, Y. Wu, B.D. Hermsmeier, M.G. Samant, G.R. Harp, S. Koranda, D. Dunham, and B.P. Tonner, Science 259, 658 (29-JAN-1993).

16. L. Baumgarten, C.M. Schneider, M. Petersen, F. Schafers, and J. Kirschner, Phys. Rev. Lett. 65, 492 (1990). 
17. G.D. Waddill, J.G. Tobin, and D.P. Pappas, Phys. Rev. B 46, 552 (1992).

18. G.D. Waddill, J.G. Tobin, and A.F. Jankowski, J. App. Phys. 74, 6999 (1993).

19. P.A. Sterne, private communication.

20. A.F. Jankowski, G.D. Waddill, and J.G. Tobin, Mat. Res. Soc. Symp. Proc. 313, 227 (1993).

21. A.F. Jankowski, G.D. Waddill, and J.G. Tobin, J. Vac. Sci. Tech. A, (May 1994).

22. L.J. Terminello, G.D. Waddill, and J.G. Tobin, Nuc. Instrum. Meth. A319, 271 (1992).

23. K.G. Tirsell and V. Karpenko, Nuc. Instrum. Meth. A291, 551 (1990). 

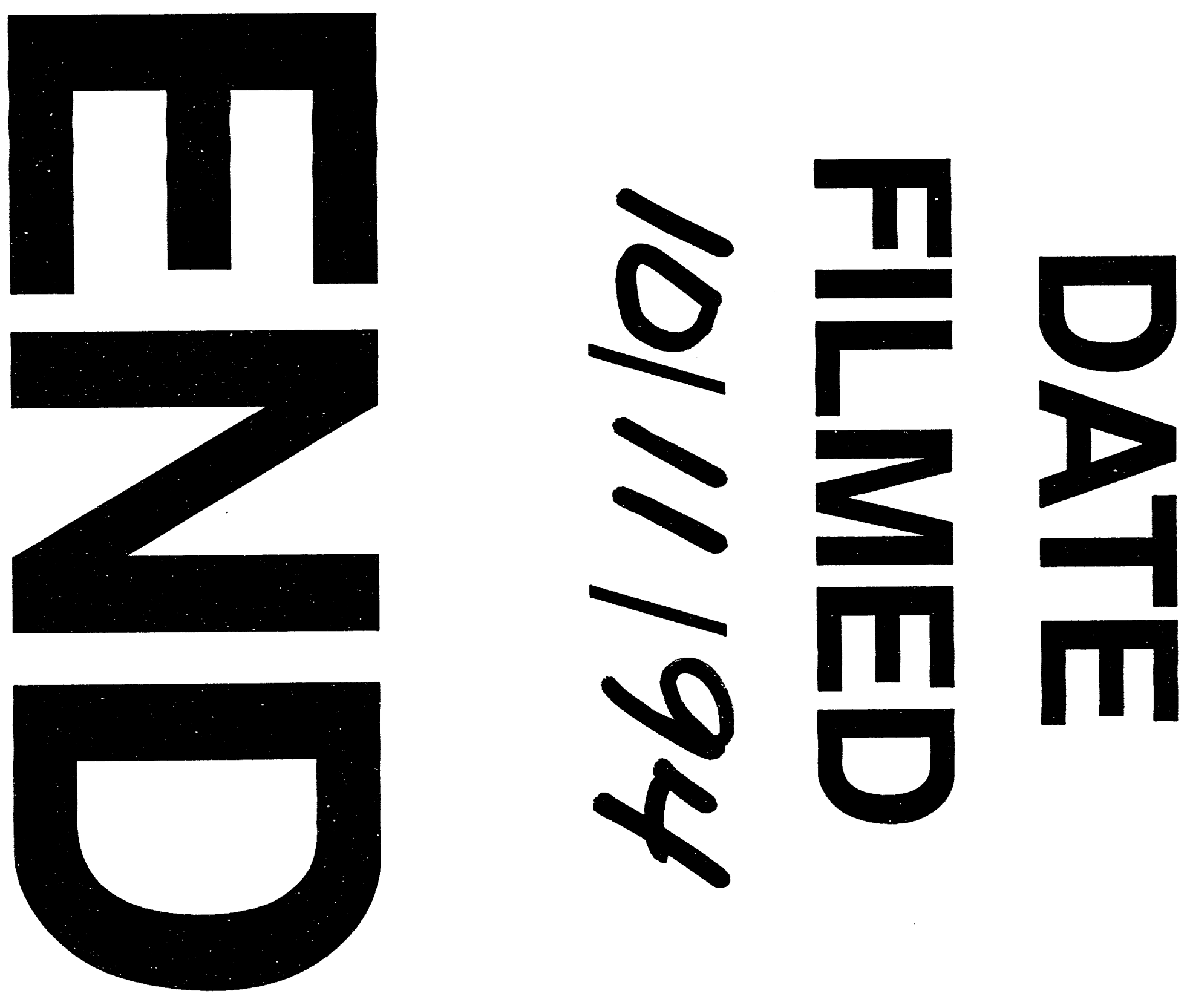
